Disponível em

http://www.anpad.org.br/rac

RAC, Curitiba, v. 14, n. 3, art. 6, pp. 495-515, Mai./Jun., 2010

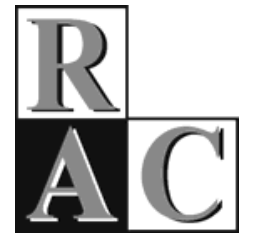

\title{
Fatores Promotores e Inibidores do Alinhamento Estratégico da Tecnologia da Informação em uma Situação de Fusão: o Caso de uma Rede Varejista
}

Enabling and Inhibiting Factors of the Strategic Alignment between Information Technology Strategy and Entrepreneurial Strategy in a Situation of Fusion of Companies in a Retail Environment

* Endereço: Christiane Maria Leite Pereira

Rua General Luis Mallet, 28/2101, Boa Viagem, Recife/PE, 51021-420. E-mail: christiane_mestrado@yahoo.com.br

Copyright (C) 2010 RAC. Todos os direitos, inclusive de tradução, são reservados. É permitido citar parte de artigos sem autorização prévia desde que seja identificada a fonte. 


\title{
RESUMO
}

Este estudo buscou identificar fatores promotores e inibidores do alinhamento estratégico entre a tecnologia da informação e a estratégia empresarial em uma situação de fusão de empresas em um ambiente varejista. O caso possibilitou identificar percepções do corpo gerencial acerca das características promotoras e inibidoras do alinhamento. O estudo destacou eventos nos momentos antes do processo de fusão e no seu desenrolar, tal que se pôde associar aos fatores clássicos identificados na literatura de apoio, aqui chamados de fatores recorrentes por estarem presentes nos dois instantes da análise do caso, novos fatores vislumbrados no cenário. Foram ouvidos gestores das áreas técnica e de negócios na estrutura resultante, respeitando-se a vinculação às empresas originais, a fim de se ter um conjunto de fatores identificados por área e por empresa. A singularidade do estudo de caso remonta ao fato de que embora a estrutura organizacional da empresa adquirente seja muito maior do que o da empresa adquirida, o perfil de gestão de tecnologia da informação da empresa adquirida é muito mais estruturado do que o da empresa adquirente, configurando um interessante cenário para a pesquisa.

Palavras-chave: alinhamento; fatores promotores e inibidores.

\begin{abstract}
This study identifies both enabler and inhibitor factors to the strategic alignment of information technology with existing entrepreneurial strategy in a takeover environment, i.e., the merger of two companies within a retail environment. The characteristics of the enabler and inhibitor factors for alignment were identified by means of an analysis of managerial team perceptions. The results suggest the presence of factors that are associated with those considered classic found in the literature review. The occurrence of these factors was recorded both prior to and during the initial merger process and they have been denominated, therefore, as recurrent elements. New characteristics, however, were also discovered in the takeover scenario that only appeared after the merger as formulated. Both IT managers and division heads from the post-merger business structure were interviewed. The link of each respondent to his original company was recorded so as to produce an effective set of factors that could be identified by both specific division and company. The uniqueness of the case study has to do with the fact that, although the organizational structure of the acquiring company was much larger than that of the acquired one, the profile of the IT management team of the latter was much more structured than that of the former. This provided a very interesting research scenario.
\end{abstract}

Key words: alignment; enabling and inhibiting factors. 


\section{INTRODUÇÃO}

O atual panorama econômico mundial está sendo moldado por duas forças poderosas: tecnologia e globalização (Kotler, 1999). Diante desse cenário global e complexo e da concorrência acirrada, as empresas têm-se movido no sentido de aumentar sua eficiência, sua produtividade e seus lucros através do uso cada vez mais intenso da tecnologia da informação [TI], até mesmo, para acompanhar a evolução dos processos e do mercado.

Agora, mais do que em qualquer tempo da história recente, as organizações encaram a necessidade de se tornarem mais inovadoras e terem custos competitivos como previam Henderson e Venkatraman (1991). Para tal, a informação é elemento fundamental tanto no processo de decisão, quanto na determinação de estratégias que as tornem competitivas, além de constituir requisito para a execução de seus processos de negócios.

Em verdade, as organizações estão enfrentando um mercado competitivo, globalizado e turbulento e, nesse cenário, necessitam de informações oportunas que auxiliem a sua gestão de forma mais efetiva. Requer-se, para tanto, que todas as suas estratégias estejam plenamente alinhadas (Rezende, 2002), o que torna o alinhamento entre a estratégia de tecnologia da informação e a estratégia empresarial uma exigência de mercado.

O alinhamento entre a tecnologia da informação e os negócios examina a relação estratégica entre as funções de tecnologia da informação e os objetivos de negócio. Este alinhamento sofre impactos da estrutura organizacional, da alocação de recursos, do planejamento, da tecnologia e, em especial, da cultura organizacional vigente (Bruhn, 2004), existindo, nesse processo, elementos promotores e elementos inibidores.

Visando compreender a busca de vantagens competitivas através do alinhamento entre estratégia da tecnologia da informação e estratégia empresarial, a proposta deste trabalho é identificar, à luz da percepção do corpo gerencial, fatores promotores e inibidores do alinhamento dessas estratégias, em um estudo de caso de fusão de empresas, campo no qual a problemática em estudo ainda é pouco discutida e pouco praticada, sendo, portanto, merecedora de aprofundamento. A estratégia de pesquisa desse processo, rico em detalhes e de complexas relações, buscou evidenciar as percepções dos envolvidos nos momentos que antecederam a fusão e durante a implementação do processo.

\section{REFERÊNCIAS CONCEITUAIS}

Vários autores têm estudado o alinhamento entre tecnologia da informação e estratégia empresarial. A maioria deles aponta como principal desafio para esse alinhamento a falta de compartilhamento de informações entre a área de TI e as áreas de negócios da organização.

\section{Estratégia}

Há muitas teorias sobre o que é estratégia e como ela pode ajudar as organizações a se manterem competitivas. Segundo Osgood (2004), embora frequentemente os termos estratégia e plano estratégico possuam uma única definição, constituem, na realidade, conceitos distintos. Estratégia é aquilo que define o que a organização fará e não fará, a partir do mapeamento dos passos a serem seguidos e que levará ao atingimento das metas organizacionais. A seu turno, o plano estratégico descreve como as ações serão feitas e oferece as direções detalhadas para priorizar esses passos.

As crescentes dificuldades enfrentadas pelas empresas em face do ambiente externo cada vez mais mutável e descontínuo, reconhecidas por administradores e acadêmicos, têm exigido novas regras e 
diretrizes de decisão para o desenvolvimento organizacional (Ansoff, 1990). Como consequência, o interesse pelo campo da estratégia tem sido fortalecido e se consolidou, passando a ser um requisito importante para as organizações em sua preparação para enfrentar a competição e a concorrência.

A estratégia competitiva destina atenção especial às ações que a empresa tentará utilizar para ter sucesso em cada uma de suas áreas de negócio, visem elas à maximização da participação no mercado, ao crescimento, à diferenciação de mercado ou diferenciação de produtos e serviços (Ansoff, 1990). Cada organização possui, de modo implícito ou explícito, uma estratégia competitiva dinâmica e única (Osgood, 2004), com a qual busca uma fórmula ampla para competir, definindo quais os objetivos almejados e como fazer para alcançá-los por meios planejados ou emergentes nas atividades organizacionais (Porter, 1986).

Outros pontos a serem destacados para aumentarem essa competitividade são as estratégias de fusão e aquisição que estão sendo adotadas como estratégias de entrada das empresas internacionais no mercado brasileiro.

Conceitualmente, fusão é uma estratégia por meio da qual duas firmas concordam em integrar suas operações em base relativamente equivalente, porque têm recursos e capacidades que, juntos, podem criar uma vantagem competitiva mais forte (Hitt, Ireland, \& Hoskisson, 2002).

No caso das fusões internacionais, ocorre também uma transferência de conhecimentos e habilidades de uma organização de um país, para outra organização de outro país, embora ocorra, em contrapartida, um aprendizado mútuo de técnicas e conhecimentos importantes (Suen \& Kimura, 1997).

\section{Tecnologia}

A tecnologia é um componente vital na atual configuração competitiva e produtiva das organizações. Mediante o uso de componentes diversos e de distintas implementações, a tecnologia tem assegurado maior competitividade, maior agilidade processual interna e proporcionado a produção de um arsenal específico de informações gerenciais. Também tem influenciado decisivamente na produção de bens e serviços e contribuído para a rentabilidade do negócio e expansão dos horizontes organizacionais.

Em curto espaço de tempo, a tecnologia ganhou força, gerando benefícios em termos de eficiência, eficácia e transformação, atingindo indivíduos, unidades funcionais e a organização como um todo; indo além da simples automação, provocando mudanças organizacionais e dotando as pessoas de melhores informações, constituindo, pois, a base para o aperfeiçoamento do processo de decisão e da produção de bens e serviços (Walton, 1993).

Dentre as tecnologias, a tecnologia da informação [TI] proporciona valor estratégico para todas as partes do negócio e, embora ainda seja usada para reduzir custos, seu atual foco é incrementar qualidade de produtos e serviços, melhorar operações de clientes, integrar fornecedores e tornar possível a aprendizagem organizacional. O uso estratégico da TI produz um poderoso impacto no negócio e amplia o valor da informação (Luftman, Lewis, \& Oldach, 1993), além de influenciar os recursos das empresas de maneira inimitável (Grover \& Lederer, 2003).

\section{Alinhamento Estratégico}

Apesar de ter sido estudada e documentada desde o final dos anos 1980, a importância do alinhamento estratégico continua ainda a ser apontada como uma das questões-chave enfrentadas pelos executivos de negócios e de informação (Chan, 2002; Papp \& Luftman, 1995). O alinhamento estratégico permite que a tecnologia da informação e os negócios se tornem parceiros. Isso proporciona que novas tecnologias resultem em novas oportunidades comerciais, gerando melhores condições para se obter vantagem competitiva. 
Alinhamento estratégico corresponde à adequação estratégica e à integração funcional entre os ambientes externo (mercado, política, fornecedores) e interno (estrutura administrativa, recursos financeiros, tecnológicos e humanos) para desenvolver e maximizar a performance organizacional (Henderson \& Venkatraman, 1993; Luftman et al., 1993).

Em visão mais moderna, o alinhamento estratégico é um processo evolucionário e dinâmico que requer forte apoio da alta gestão das organizações, associado a boas relações de trabalho, liderança forte, prioridade adequada, confiança e efetiva comunicação, além do entendimento do ambiente de negócios (Luftman, 2000).

O alinhamento estratégico tornou-se requisito básico para as organizações, a partir da constatação de que elas estavam desenvolvendo tecnologias que não apoiavam suas estratégias de negócios, por priorizarem aspectos técnicos em detrimento das necessidades de negócios (Luftman et al., 1993). Tal falta de sincronia criou muita tensão para os postos executivos, resultando em perda de retorno sobre o investimento em tecnologia da informação.

\section{Fatores Promotores e Inibidores}

Em pesquisa longitudinal por cinco anos consecutivos, Luftman, Papp e Brier (1999) encontraram fatores organizacionais cuja presença ou forte atenção a eles dedicada exercia papel promotor e, em contrapartida, cuja ausência ou fraca atenção a eles prestada exercia papel inibidor no alinhamento estratégico da tecnologia da informação com o negócio. Os principais fatores detectados naquele estudo foram: (a) apoio da alta gestão aos assuntos de tecnologia da informação; (b) liderança na área de tecnologia da informação; (c) entendimento do negócio pela tecnologia da informação; (d) relação de parceria entre tecnologia da informação e negócios; (e) prioridade de projetos de tecnologia da informação; (f) participação da tecnologia da informação no desenvolvimento da estratégia de negócio.

Reich e Benbasat (2000) destacaram outros fatores promotores do alinhamento estratégico, quais sejam: comunicação clara e compartilhamento de conhecimento entre executivos de negócios e de tecnologia da informação, sucesso na implementação de TI e conexão entre processos de planejamento de tecnologia da informação e empresarial.

Essa participação cruzada implica o compartilhamento de conhecimentos sobre ambos os métodos de planejamento (Grover \& Lederer, 2003) e ajuda a garantir que as estratégias serão implementadas corretamente (Reich \& Benbasat, 1996). Assim, a participação dos profissionais da área de TI e das áreas de negócio, de forma equânime na construção dos planejamentos estratégicos, é vital para o uso competitivo das estratégias.

Brodbeck, Hoppen, Oliveira e Majdenbaum (2003) consideram ainda outros elementos contribuintes da promoção do alinhamento: comprometimento das pessoas com o atingimento das metas, sincronização dos recursos entre as ações de negócios e de tecnologia da informação, instrumentação da gestão para o eficiente monitoramento e ajuste contínuo dos processos e postura decisória proativa.

Por seu turno, Reich e Benbasat (2000) ressaltam como fatores inibidores a falta de participação dos executivos de TI nos planejamentos dos processos críticos de negócio e o pouco conhecimento dos executivos de negócio da estratégia de TI. Outro importante aspecto apontado pelos autores é a falha na implementação dos sistemas de informação, o que reduz a credibilidade do departamento de TI e é uma ameaça para a existência de um relacionamento entre as áreas no ambiente de trabalho.

Luftman (1997) argumenta que barreiras adicionais para o alinhamento são a dificuldade da área de TI em acompanhar as mudanças que ocorrem no ambiente de negócio da empresa e a baixa habilidade de se relacionar e se comprometer de forma adequada com essas mesmas áreas de negócio.

Enfim, para desenvolver a tarefa de alinhamento estratégico requer-se que as organizações focalizem na maximização dos fatores promotores e com atenção redobrada na minimização dos fatores 
inibidores do processo (Luftman, 2000). É pelo conhecimento do grau de maturidade do alinhamento estratégico entre TI e negócio e do impacto desse alinhamento no resultado, produtividade e lucratividade, que as organizações podem avaliar suas atividades práticas e tomar decisões para a ampliação das relações estratégicas entre tecnologia da informação e negócio (Chan, Huff, Barclay, \& Copeland, 1997; Luftman \& Brier, 1999).

Toda argumentação contida nesta seção converge para a montagem exibida na Figura 1, a qual resume os principais fatores promotores e inibidores do alinhamento estratégico entre a TI e o negócio levantados na bibliografia de referência.

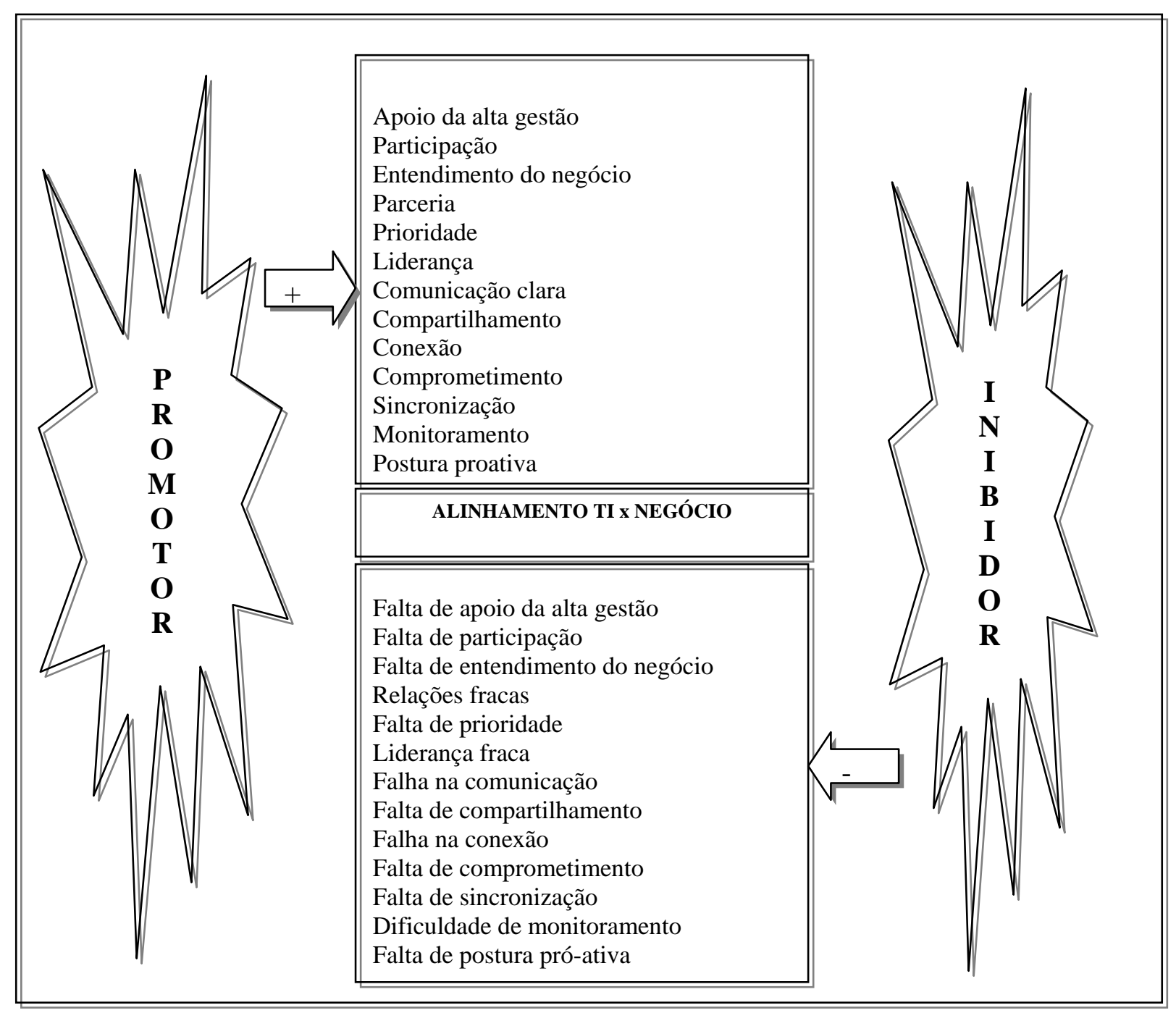

Figura 1. Principais Fatores Promotores e Inibidores do Alinhamento Estratégico

Fonte: compilação efetuada a partir de Luftman, J. (1997). Align in the sand, leadership series computerworld. ABI/INFORM Global, 3(2), pp. 3-4; Luftman, J., Papp, R., \& Brier, T. (1999). Enablers and inhibitors of business-it alignment. Communications of the Association for Information Systems, 1(11), pp. 4-15. Reich, B. H., \& Benbasat, I. (2000). Factors that influence the social dimension of alignment between business and information technology objectives. MIS Quarterly, 24(1), pp. 3-5; Brodbeck, A. F., Hoppen, N., Oliveira A. S., \& Majdenbaum, A. (2003, setembro). Alinhamento entre objetivos organizacionais e sistemas de informação: um estudo de múltiplos casos. Anais do Encontro Nacional da Associação Nacional de Pós-Graduação e Pesquisa em Administração, Atibaia, SP, Brasil, 27, pp. 6-7.

É com este aporte conceitual advindo da literatura e com o conjunto de fatores identificados na Figura 1 que se tecem, no item seguinte, considerações sobre a metodologia adotada. 


\section{MetOdOlOGIA DA PESQUISA}

Esta pesquisa tem caráter exploratório, porque visa identificar fatores promotores e fatores inibidores do alinhamento estratégico, a partir da percepção de um pequeno grupo de respondentes do corpo gerencial das empresas Wal-Mart Brasil e Bompreço S.A., que estavam, e ainda se encontram, em processo de fusão. Valeu-se de uma abordagem qualitativa e utilizou a estratégia de estudo de caso para sua implementação.

O estudo de caso caracterizou-se como um estudo de caso único, que mirou a fusão do Bompreço S.A. (empresa adquirida) e do Wal-Mart Brasil (empresa adquirente). Trata-se de estudo de um processo de fusão entre empresas com características ímpares para os padrões do segmento varejista regional, inusitado no que diz respeito à plenitude e abordagem de estudo (até onde se pôde identificar em termos da literatura nacional) e revelador, como caracterizável a partir de Yin (2001), pelas razões arguídas nos próximos parágrafos.

As empresas envolvidas têm grande dimensão e, guardadas as proporções, intensas e marcantes representatividades em seus ambientes originais. Como ilustração, destaque-se que, antes da fusão, o Bompreço tinha cerca de 22.000 associados e 118 lojas e o Wal-Mart Brasil tinha cerca de 8.000 associados e 20 lojas, e a área de TI do Bompreço S.A. tinha cerca de duzentos profissionais, enquanto a área de TI do Wal-Mart Brasil era muito menor com cerca de vinte profissionais, conforme registros documentais das duas empresas.

Verifica-se maior vulto da função TI na empresa adquirida; ainda assim, quando olhado o porte das empresas, nota-se claramente que a empresa adquirente é muito maior em volume e estratégia de negócios, especialmente considerando o aspecto multinacional. É justamente esta surpreendente diferença que instiga a enveredar pelo estudo de caso. A empresa adquirida tinha sua área de TI muito mais bem estruturada que a empresa adquirente, tornando bem mais complexo o processo de fusão e, provavelmente, o do alinhamento, uma vez que a relação de poder no processo de fusão estaria em oposição à maturidade técnica percebida.

Este é o aspecto revelador do caso: entender o alinhamento estratégico entre TI e negócio em processo de fusão, quando a relação de poder é inversa à capacidade técnica em TI. Esperava-se que a existência dessa característica contribuísse para a emergência de novos fatores promotores e inibidores do alinhamento da estratégia de TI e do negócio.

A opção por observar esse fenômeno à luz de um único e revelador caso, em adição a todos os argumentos prévios, caracteriza-se ainda por um propósito instrumental: o estudo de caso traz elementos para um foco pouco explorado da questão. Nesses casos, como afirma Stake (1994, p. 261), "o número de casos é secundário, servindo apenas de suporte para facilitar o nosso entendimento sobre o ponto pouco explorado. A escolha é feita para avançar o nosso entendimento daquele ponto”.

É de se notar também que, como o estudo ocorreu em plena vigência do processo de fusão das empresas, estavam vívidas as impressões do estágio anterior à fusão e toda tensão do processo em andamento, suplantando, dessa forma, o eventual viés associado ao uso da tática de entrevista retrospectiva. Assim, o aspecto de marcante presença dos eventos foi suficiente para se contrapor à aparente disfunção aliada à recordação dos fatos e justifica a opção de imersão no caso em um único momento, em busca de seus elementos reveladores.

Por fim, em função da acessibilidade dos pesquisadores ao fenômeno, mais um fato tornou categórica a escolha do caso único: se não fosse nos moldes aqui revelados, dificilmente esse caso ficaria acessível à investigação científica. 


\section{Atores Pesquisados}

Os roteiros para as entrevistas semi-estruturadas de coleta de dados foram gerados a partir do encadeamento teórico dos fatores identificados na Figura 1. As entrevistas foram aplicadas nas principais áreas de negócio e na área de TI, considerando a empresa já unificada. O público-alvo totalizou 23 executivos respondentes, para os quais se observaram, sobremaneira, os seus vínculos prévios às empresas fundidas. Na área de negócios, 8 (oito) entrevistados pertenciam ao Bompreço S.A. e 8 (oito) pertenciam ao Wal-Mart Brasil. Já na área de TI, 4 (quatro) entrevistados pertenciam ao Bompreço e 3 (três) ao Wal-Mart Brasil.

\section{Desenho da Pesquisa}

O desenho de pesquisa é uma forma esquemática que mostra como se empreende a execução de uma investigação. Auxilia no avaliar o escopo temporal de realização e no sequenciar as diversas etapas dos procedimentos. A Figura 2 exibe o desenho da presente pesquisa.

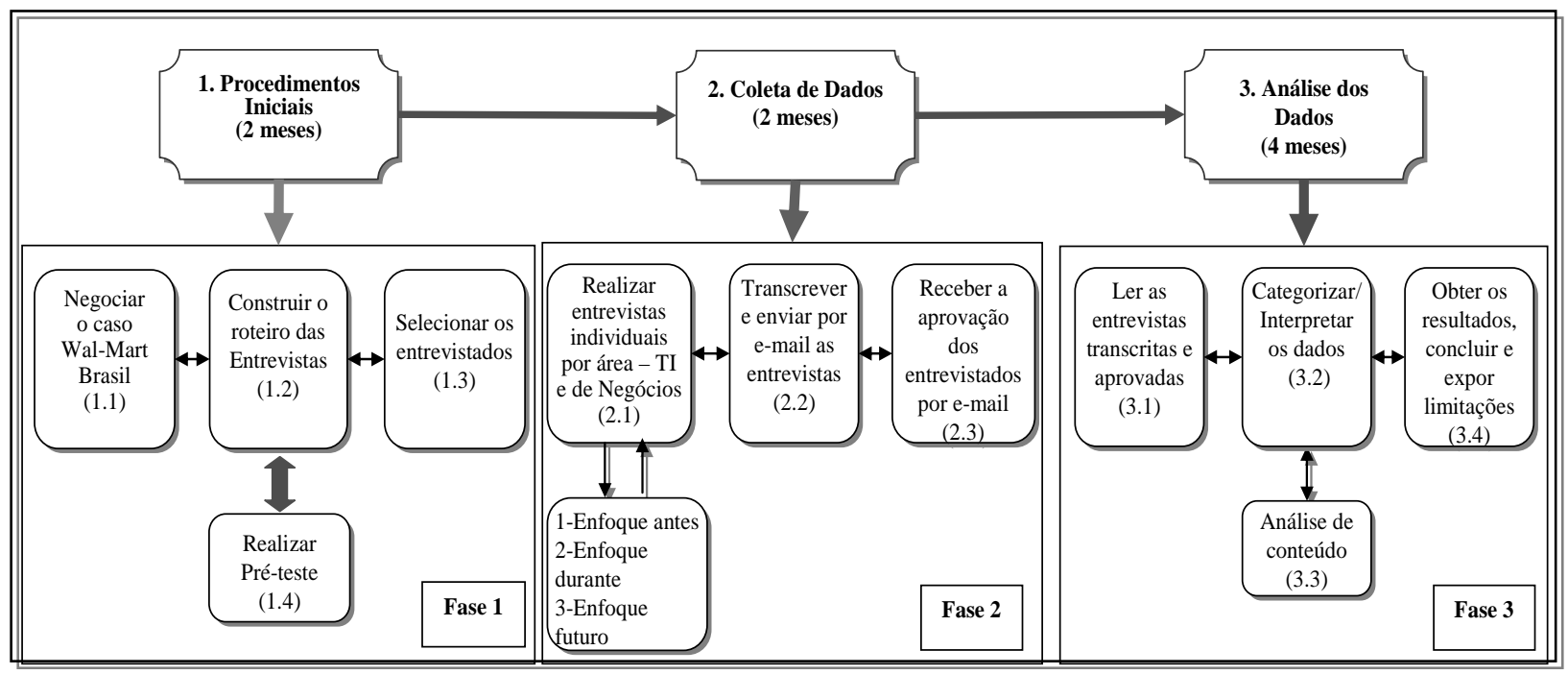

Figura 2. Desenho da Pesquisa

Fonte: Pereira, C. M. L. (2006). Fatores promotores e inibidores do alinhamento estratégico da tecnologia da informação em uma situação de fusão: o caso de uma rede varejista. Dissertação de mestrado, Universidade Federal de Pernambuco, Recife, PE, Brasil, p. 66.

\section{Procedimento de Coleta e Instrumento de Pesquisa}

Um protocolo de caso foi construído, respeitando-se a sequência exibida na Figura 2, para assegurar confiabilidade à pesquisa. Nele todos os passos e decisões foram documentados e estipuladas as condições para possibilitar a eventual repetição do trabalho nos moldes aqui consignados.

As entrevistas foram realizadas com os executivos de negócio e de TI. O roteiro aplicado foi dividido em quatro blocos e dentro desses blocos existiam perguntas comuns e perguntas específicas por área ouvida (TI e negócio). Os roteiros foram pré-avaliados por docentes e mestrandos da instituição de ensino que ancorou a pesquisa.

O primeiro bloco recolheu dados gerais do entrevistado e seu entendimento sobre o que seria alinhamento entre a estratégia de TI e a estratégia empresarial. O segundo bloco visou identificar os fatores que promoviam e inibiam o alinhamento entre a estratégia de TI e a estratégia de negócio antes da fusão. Correspondeu a solicitar às pessoas que recordassem o passado recente, quando as empresas anunciaram a convivência das operações em feição dual. 
Já o terceiro bloco destinou-se a identificar os fatores durante a eclosão do processo de fusão. Nesse ínterim, quando solicitado, o entrevistador relembrou ao respondente as opiniões por ele já emitidas sobre o momento antes da fusão. Isso foi possível porque houve um intervalo de 15 minutos entre a aplicação das questões dos blocos 2 e 3 das entrevistas. A conversa informal nesse intervalo também serviu para a análise dos dados.

Por fim, o quarto bloco recolheu a expectativa do respondente com relação à forma como será o alinhamento após o término de todo o processo de fusão.

A opção de realizar uma única sessão de entrevista com cada respondente impôs-se devido às dificuldades de alocação de tempo nas pesadas agendas dos executivos entrevistados. Assim, mesmo que algumas das percepções capturadas também tenham sido baseadas em reminiscências (às vezes nostálgicas para os respondentes da empresa adquirida), tal variante de coleta propiciou o confronto de caráter quase experimental das idéias e foi rica por revelar posicionamentos e reposicionamentos de fatores no tempo e no processo.

Todas as entrevistas foram conduzidas pela equipe de pesquisa e gravadas mediante autorização. Após a transcrição das entrevistas, os seus conteúdos foram enviados por e-mail para confirmação dos entrevistados. Também por $e$-mail, os entrevistados retornaram algumas considerações e aprovaram o conteúdo das transcrições, configurando-se então uma espécie de validação de conteúdo coletado.

\section{Análise dos Dados}

O tratamento dos dados recolhidos foi efetuado com o uso da técnica de análise de conteúdo. Na prática, o que ocorreu foi um exercício de reconstrução do material colhido, por meio da categorização e posterior agrupamento de palavras, temas ou itens, na busca da interpretação da mensagem, considerando o contexto dos entrevistados. Foram feitos recortes representativos dos textos originais, a fim de fazer emergir as categorias a serem analisadas.

Operacionalmente houve a associação entre os excertos das entrevistas e a significação dos fatores promotores e inibidores do alinhamento entre a estratégia de tecnologia da informação e a estratégia empresarial.

O primeiro passo da análise foi associar os recortes que continham semelhança em uma única planilha, para posterior criação das categorias. A segunda etapa da análise, a categorização, visou associar os conjuntos de semelhanças encontrados na planilha com os fatores provenientes da literatura. Para tal, um pesquisador fez o enquadramento a partir dos excertos e os consolidou. Um segundo pesquisador buscou evidenciar os excertos consolidados nos fatores provenientes da literatura (Figura 1) e, por fim, ambos os pesquisadores fizeram o mapeamento dos fatores identificados vis-àvis sua efetiva aparição (surgimento no momento antes da fusão e recorrência durante a fusão) ou sua emergência (surgimento não previsto durante o processo de fusão).

Para finalizar, foi feita uma interpretação final de todo o material, a fim de identificar quais fatores eram especificamente relacionados ao caso de fusão de empresas.

\section{RESULTADOS DO ESTUDO}

Os resultados apresentados referem-se à percepção dos entrevistados sobre dois momentos: antes da fusão das empresas e no seu desenrolar. A partir dessas percepções, são listados fatores promotores e inibidores do alinhamento entre a estratégia de TI e a estratégia empresarial, nos momentos relatados. No final do relato, também é exibida a síntese da expectativa dos entrevistados sobre o eventual alinhamento após o término de todo o processo de fusão entre as empresas. 


\section{Fatores Identificados antes da Fusão das Empresas}

Nesta seção, foi sintetizada a percepção do corpo gerencial quanto ao alinhamento entre a estratégia de TI e a estratégia empresarial e identificados os fatores promotores e inibidores do alinhamento antes da fusão, após a categorização das respostas dadas.

Os entrevistados, tanto do Bompreço quanto do Wal-Mart Brasil, concordavam que existia alinhamento entre a estratégia de TI e a estratégia empresarial. De fato, a expressiva maioria dos entrevistados (20) respondeu que existia alinhamento em suas respectivas empresas antes do processo de fusão, enquanto uma minoria concentrada em áreas não-chave do negócio, em ambas as empresas, ponderou pela não existência do alinhamento. Essa é a primeira evidência de que o alinhamento é mais forte nas áreas-chave do negócio.

Os fatores que afetavam o alinhamento da estratégia de TI com a estratégia de negócio identificados nas entrevistas, quando o foco foi o momento antes da fusão, agrupados por empresa, são exibidos na Tabela 1, no qual há sete grupos de percepções distintas, identificáveis pela mesma configuração de símbolos nas respectivas linhas do quadro.

Tabela 1

Fatores que Afetavam o Alinhamento antes da Fusão

\begin{tabular}{lcccc}
\hline Fatores Identificados - Antes da fusão & $\begin{array}{c}\text { Bompreço } \\
\text { (TI) }\end{array}$ & $\begin{array}{c}\text { Bompreço } \\
\text { (Negócio) }\end{array}$ & $\begin{array}{c}\text { Wal-Mart } \\
\text { (TI) }\end{array}$ & $\begin{array}{c}\text { Wal-Mart } \\
\text { (Negócio) }\end{array}$ \\
\hline Apoio da alta administração & $\checkmark$ & $\checkmark$ & & \\
Conhecimento das metas & $\checkmark$ & $\checkmark$ & & \\
Qualificação dos profissionais & $\checkmark$ & $\checkmark$ & & \\
Autonomia da área de TI & $\checkmark$ & $\checkmark$ & & $\checkmark$ \\
Planejamento & $\checkmark$ & & $\checkmark$ & $\checkmark$ \\
Postura dos profissionais & $\checkmark$ & & $\checkmark$ & $\checkmark$ \\
Prioridade do negócio & & & $\checkmark$ & $\checkmark$ \\
Sinergia entre as áreas & $\checkmark$ & $\checkmark$ & $\checkmark$ & $\checkmark$ \\
Limitação dos recursos & $\checkmark$ & $\checkmark$ & & \\
Comunicação & & & $\checkmark$ & \\
Tratamento das necessidades locais & & & & $\checkmark$ \\
Centralização da TI & & & & \\
Uso de metodologia nos projetos & $\checkmark$ & & & \\
Gestão de Projetos & $\checkmark$ & $\checkmark$ & & \\
\hline
\end{tabular}

Nota. Fonte: Pereira, C. M. L. (2006). Fatores promotores e inibidores do alinhamento estratégico da tecnologia da informação em uma situação de fusão: o caso de uma rede varejista. Dissertação de mestrado, Universidade Federal de Pernambuco, Recife, PE, Brasil, p. 82.

A análise dos grupos remete à compreensão de efeitos que são notados pela adquirida em suas duas áreas (apoio da alta administração, conhecimento das metas, qualificação dos profissionais e autonomia da área de TI), ou notadamente visíveis pela empresa adquirente também em ambas as áreas (comunicação, tratamento das necessidades locais e centralização da TI). Não existe um fator que seja percebido igualmente pelas 4 áreas pesquisadas, embora haja aquele que é massivamente atrelado à área de TI da adquirida (uso de metodologia nos projetos) e outro que aparece só na área de negócio da adquirente (prioridade do negócio). 
Há, ainda, os fatores que só aparecem na área de TI da adquirida e na área de negócio da adquirente (planejamento e postura dos profissionais), como também os que são visíveis em todo o Bompreço e só na área de negócio do Wal-Mart Brasil (sinergia entre as áreas e limitação dos recursos). O último grupo aparece em todo o Bompreço e só na área de TI do Wal-Mart Brasil (gestão de projetos).

Assim, considerando a análise das entrevistas de todas as áreas das duas empresas para o período antes da fusão, os fatores levantados foram rotulados como promotores ou inibidores, em aderência ao caso (emergentes) e à literatura (pré-definidos), como exibido na Figura 3.

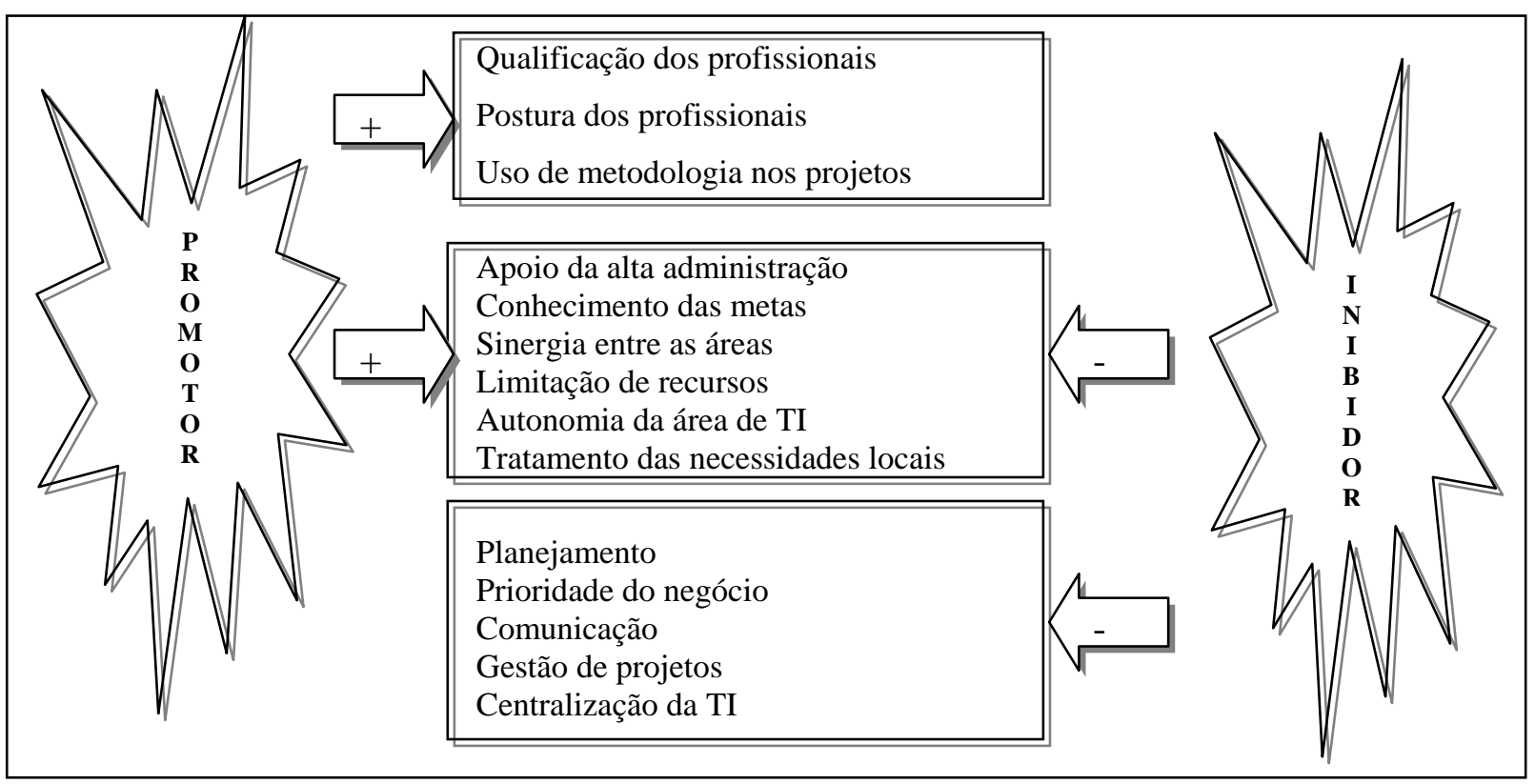

Figura 3. Fatores Promotores e Inibidores do Alinhamento antes da Fusão

Fonte: Pereira, C. M. L. (2006). Fatores promotores e inibidores do alinhamento estratégico da tecnologia da informação em uma situação de fusão: o caso de uma rede varejista. Dissertação de mestrado, Universidade Federal de Pernambuco, Recife, PE, Brasil, p. 85.

Os fatores qualificação e postura dos profissionais foram citados como promotores pelos respondentes de ambas as empresas, haja vista a importância das pessoas no processo de alinhamento. O fator uso de metodologia nos projetos só foi citado como promotor pela área de TI do Bompreço, que usava fortemente essa técnica nos seus projetos, não sendo sequer citado pelos entrevistados do Wal-Mart Brasil. Já os fatores planejamento e gestão de projetos foram comentados pelos respondentes das áreas de TI das duas empresas como inibidores do alinhamento. Tal fato também foi percebido com o mesmo matiz inibidor pela área de negócio do Bompreço; no entanto, as áreas de negócio do Wal-Mart Brasil não conseguiram visualizar o fator gestão de projetos, pois as estratégias das suas áreas tinham de se adequar à realidade dos sistemas globais do Wal-Mart e, por isso, havia poucos projetos de TI no WalMart Brasil antes da fusão com o Bompreço. Já os fatores prioridade do negócio, comunicação e centralização da área de TI só foram citadas pelos entrevistados do Wal-Mart Brasil, que tinham dependência dos sistemas globais e não tinham suas necessidades locais priorizadas.

Ainda no período antes da fusão, notou-se certa indefinição de posicionamento da maioria dos fatores identificados em relação à promoção ou inibição do alinhamento, gerando o conjunto tachado de fatores indefinidos.

De fato, detalhando os aspectos de tal indefinição percebeu-se que só os entrevistados do Bompreço citavam os fatores: existência da autonomia da área de TI, apoio da alta administração e conhecimento das metas, algo típico de uma empresa que tinha autonomia local maior que a empresa adquirente na área de TI. Já o fator sinergia entre as áreas foi citado como o mais importante para garantir o alinhamento e o fator limitação de recursos foi citado como o mais forte entrave para obtê-lo. Finalizando a observação sobre os fatores ditos indefinidos no período antes da fusão, relata-se que só 
os entrevistados do Wal-Mart Brasil visualizaram que havia dificuldade no tratamento das necessidades locais.

Na próxima seção, será tratada a informação atinente ao período durante a fusão e analisados os fatores sob duas óticas: aqueles que foram mantidos, a partir de seu surgimento antes da fusão, e os novos fatores que surgiram no período da fusão das duas empresas.

\section{Fatores Emergentes durante a Fusão das Empresas}

Ambas as empresas concordavam que existiam fatores específicos que afetavam o alinhamento apenas durante o processo de fusão e que estes coexistiriam com os fatores identificados antes da fusão, doravante tratados como fatores recorrentes.

Em relação aos fatores recorrentes, apenas o fator apoio da alta administração não foi citado novamente, talvez por já ser um pré-requisito para a realização de processos de fusão. Os demais fatores foram citados e, mais uma vez, reagruparam-se em 7 grupos de percepções. No entanto, para os novos grupos formados, há divergências entre o arranjo atual e aquele obtido na análise antes da fusão.

De fato, os novos arranjos mostram fatores em três grupos de maior representatividade e quatro fatores em ambiência isolada. O primeiro grupo congrega cinco fatores (conhecimento das metas, sinergia entre as áreas, comunicação, tratamento das necessidades locais e centralização da TI), que têm visibilidade em todas as áreas das duas empresas. Repetem-se, em relação à Tabela 1, as percepções referentes aos fatores comunicação, atenção às necessidades locais e centralização da tecnologia no nível da adquirente, caracterizando-se tal fato como expansão da visão inicial para a empresa adquirida. No que concerne ao momento antes da fusão, o fator conhecimento das metas passou a ter visão ampla, migrando de visão apenas Bompreço para a visão Bompreço e Wal-Mart Brasil. Significativamente o fator sinergia passou também a ser percebido pela área de TI do Wal-Mart Brasil.

O outro grande arranjo corresponde a dois grupos de percepção, cada qual com dois fatores. O subgrupo dos fatores planejamento e postura dos profissionais e o subgrupo dos fatores qualificação dos profissionais e autonomia da área de TI projetam rigorosamente os mesmos enfoques percebidos no momento antes da fusão, valendo, então, a interpretação já apresentada.

Também três fatores isolados (limitação de recursos, uso de metodologia nos projetos e gestão de projetos) mantêm rigorosamente o mesmo posicionamento do momento antes da fusão e, por fim, o fator prioridade do negócio, que antes era visível exclusivamente pelas áreas de negócio do Wal-Mart Brasil, agora passou a ser também visível pelas áreas de negócio do Bompreço.

A Tabela 2 incorpora os dados da Tabela 1 e sintetiza o exame feito sobre os fatores recorrentes no processo de fusão. A simbologia adotada deixa antever, na posição mais à esquerda, a ocorrência do fator antes da fusão, ao passo que, na posição mais à direita, se mostra o posicionamento do fator durante o processo de fusão.

Tabela 2

Fatores Recorrentes que Afetam o Alinhamento durante a Fusão

\begin{tabular}{lcccc}
\hline $\begin{array}{c}\text { Fatores mantidos durante fusão } \\
\text { (fatores recorrentes) }\end{array}$ & $\begin{array}{c}\text { Bompreço } \\
\text { (TI) }\end{array}$ & $\begin{array}{c}\text { Bompreço } \\
\text { (Negócio) }\end{array}$ & $\begin{array}{c}\text { Wal-Mart } \\
\text { (TI) }\end{array}$ & $\begin{array}{c}\text { Wal-Mart } \\
\text { (Negócio) }\end{array}$ \\
\hline Conhecimento das metas & $\checkmark / \checkmark$ & $\checkmark / \checkmark$ & $/ \checkmark$ & $/ \checkmark$ \\
Sinergia entre as áreas & $\checkmark / \checkmark$ & $\checkmark / \checkmark$ & $/ \checkmark$ & $\checkmark / \checkmark$ \\
Comunicação & $/ \checkmark$ & $/ \checkmark$ & $\checkmark / \checkmark$ & $\checkmark / \checkmark$ \\
Tratamento das necessidades locais & $/ \checkmark$ & $/ \checkmark$ & $\checkmark / \checkmark$ & $\checkmark / \checkmark$ \\
\hline
\end{tabular}

Continua 


\section{Tabela 2 (continuação)}

\begin{tabular}{|c|c|c|c|c|}
\hline $\begin{array}{l}\text { Fatores mantidos durante fusão } \\
\text { (fatores recorrentes) }\end{array}$ & $\begin{array}{l}\text { Bompreço } \\
\text { (TI) }\end{array}$ & $\begin{array}{l}\text { Bompreço } \\
\text { (Negócio) }\end{array}$ & $\begin{array}{l}\text { Wal-Mart } \\
\text { (TI) }\end{array}$ & $\begin{array}{l}\text { Wal-Mart } \\
\text { (Negócio) }\end{array}$ \\
\hline Centralização da TI & $/ \checkmark$ & $/ \checkmark$ & $\checkmark / \checkmark$ & $\checkmark / \checkmark$ \\
\hline Planejamento & $\checkmark / \checkmark$ & & & $\checkmark / \checkmark$ \\
\hline Postura dos profissionais & $\checkmark / \checkmark$ & & & $\checkmark / \checkmark$ \\
\hline Qualificação dos profissionais & $\checkmark / \checkmark$ & $\checkmark / \checkmark$ & & \\
\hline Autonomia da área de TI & $\checkmark / \checkmark$ & $\checkmark / \checkmark$ & & \\
\hline Prioridade do negócio & & $/ \checkmark$ & & $\checkmark / \checkmark$ \\
\hline Limitação de recursos & $\checkmark / \checkmark$ & $\checkmark / \checkmark$ & & $\checkmark / \checkmark$ \\
\hline Uso de metodologia nos projetos & $\checkmark / \checkmark$ & & & \\
\hline Gestão de projetos & $\checkmark / \checkmark$ & $\checkmark / \checkmark$ & $\checkmark / \checkmark$ & \\
\hline
\end{tabular}

Nota. Fonte: Pereira, C. M. L. (2006). Fatores promotores e inibidores do alinhamento estratégico da tecnologia da informação em uma situação de fusão: o caso de uma rede varejista. Dissertação de mestrado, Universidade Federal de Pernambuco, Recife, PE, Brasil, p. 88.

Ainda, no que diz respeito ao momento durante a fusão, uma diretriz foi sondar se os entrevistados realmente percebiam a existência de fatores específicos de alinhamento estratégico entre a tecnologia da informação e o negócio, que só se fizessem sentir durante a ocorrência efetiva da fusão. Questionados acerca desse ponto, três respondentes, todos do Wal-Mart Brasil (2 das áreas de negócio e 1 da área de TI) responderam que não havia fatores específicos que afetassem o alinhamento apenas durante o processo de fusão. Os demais pesquisados disseram que fatores específicos existiriam durante esse processo. A Tabela 3 mostra esses fatores e, mais uma vez, a intenção de análise reuniu os fatores em grupos de percepções.

Tabela 3

Fatores Específicos que Afetam o Alinhamento durante o Processo de Fusão

\begin{tabular}{lcccc}
\hline Fatores específicos durante a fusão & $\begin{array}{c}\text { Bompreço } \\
\text { (TI) }\end{array}$ & $\begin{array}{c}\text { Bompreço } \\
\text { (Negócio) }\end{array}$ & $\begin{array}{c}\text { Wal-Mart } \\
\text { (TI) }\end{array}$ & $\begin{array}{c}\text { Wal-Mart } \\
\text { (Negócio) }\end{array}$ \\
\hline Tratamento das mudanças & $\checkmark$ & $\checkmark$ & & \\
Criação de time de integração & $\checkmark$ & $\checkmark$ & & \\
Adaptação à nova cultura & $\checkmark$ & $\checkmark$ & & \\
Administração do tempo & $\checkmark$ & $\checkmark$ & $\checkmark$ & $\checkmark$ \\
Unificação dos processos & $\checkmark$ & $\checkmark$ & $\checkmark$ & $\checkmark$ \\
Priorização dos treinamentos & $\checkmark$ & $\checkmark$ & $\checkmark$ & $\checkmark$ \\
Insegurança/Incertezas das pessoas & $\checkmark$ & $\checkmark$ & & $\checkmark$ \\
Segregação das áreas & $\checkmark$ & $\checkmark$ & & $\checkmark$ \\
Modelo de gestão focado em resultados & $\checkmark$ & $\checkmark$ & & $\checkmark$ \\
Experiência anterior de fusão & $\checkmark$ & $\checkmark$ & & $\checkmark$ \\
Foco na integração & $\checkmark$ & $\checkmark$ & & $\checkmark$ \\
\hline
\end{tabular}




\section{Tabela 3 (continuação)}

\begin{tabular}{lcccc}
\hline Fatores específicos durante a fusão & $\begin{array}{c}\text { Bompreço } \\
\text { (TI) }\end{array}$ & $\begin{array}{c}\text { Bompreço } \\
\text { (Negócio) }\end{array}$ & $\begin{array}{c}\text { Wal-Mart } \\
\text { (TI) }\end{array}$ & $\begin{array}{c}\text { Wal-Mart } \\
\text { (Negócio) }\end{array}$ \\
\hline Participação/Envolvimento das pessoas & $\checkmark$ & $\checkmark$ & $\checkmark$ \\
Consolidação das informações & & $\checkmark$ & $\checkmark$ & $\checkmark$ \\
Adoção de padrões mundiais & $\checkmark$ & $\checkmark$ & $\checkmark$ & $\checkmark$ \\
Adoção das melhores práticas & & & $\checkmark$ \\
\hline
\end{tabular}

Nota. Fonte: Pereira, C. M. L. (2006). Fatores promotores e inibidores do alinhamento estratégico da tecnologia da informação em uma situação de fusão: o caso de uma rede varejista. Dissertação de mestrado, Universidade Federal de Pernambuco, Recife, PE, Brasil, p. 90.

A primeira e principal impressão é que no momento da fusão, há nítida convergência de fatores, mesmo que ainda surjam seis grupos. Todavia, os grupos consolidação das informações, adoção de padrões mundiais e adoção de melhores práticas são, em verdade, fatores isolados que têm como item unificador a citação pelas áreas de negócio do Wal-Mart Brasil.

Após esta constatação, verifica-se, então, a existência de três grupos bem definidos. O grupo majoritário com os fatores insegurança / incertezas das pessoas, segregação das áreas, modelo de gestão focado em resultados, experiência anterior de fusão, foco na integração e participação / envolvimento das pessoas, no qual há convergência da empresa Bompreço e presença marcante das áreas de negócio do Wal-Mart Brasil.

O segundo grupo congrega os fatores tratamento das mudanças, criação de time de integração e adaptação da nova cultura. Esses fatores têm a marca de serem ignorados pelo Wal-Mart Brasil, mas estarem presentes em todas as áreas do Bompreço. Certamente vinculam-se ao processo de adaptação empresarial.

Por fim, o grupo dos fatores administração do tempo, unificação dos processos e priorização dos treinamentos surge como sendo fortemente percebido por todas as áreas das duas empresas. Tais fatores configuram-se como elementos cruciais e urgentes no processo de fusão.

A partir da compilação dos conteúdos e interpretação de suas influências no contexto em estudo, os fatores recorrentes e específicos do momento, durante o processo de fusão, puderam ser separados em fatores promotores e inibidores do alinhamento.

\section{Detalhamento dos Fatores Recorrentes}

Comparando os posicionamentos dos fatores recorrentes em termos de promoção ou inibição do alinhamento nos momentos antes da fusão e durante o processo de fusão, notam-se significativas flutuações, exibidas na Figura 4, mas destaca-se que, de acordo com a percepção resgatada, nenhum fator deixou de promover o alinhamento para inibi-lo. 


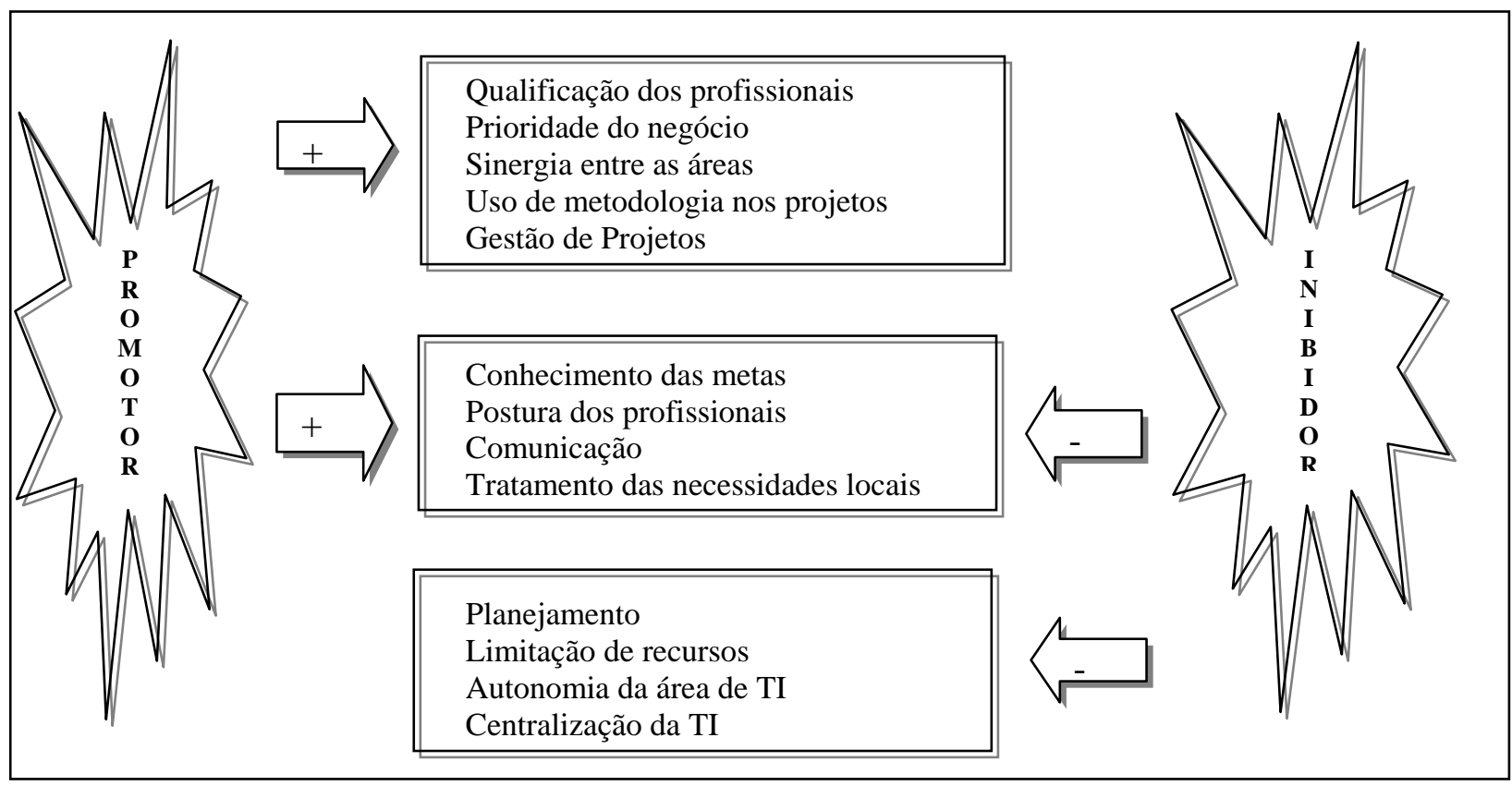

Figura 4. Fatores Promotores e Inibidores - Elementos Recorrentes

Fonte: Pereira, C. M. L. (2006). Fatores promotores e inibidores do alinhamento estratégico da tecnologia da informação em uma situação de fusão: o caso de uma rede varejista. Dissertação de mestrado, Universidade Federal de Pernambuco, Recife, PE, Brasil, p. 94.

A primeira diferença foi que a postura dos profissionais, que antes era citada como fator promotor do alinhamento, agora aparece como fator inibidor. Esse deslocamento pode ser justificado pela resistência à mudança, própria de processos de fusão.

Outro fator que migra de posição é a comunicação, o qual passa da posição de inibir o processo para um limiar de indefinição. Essa mudança é importante, porque, pelo menos, garante o início da implantação do novo modelo de gestão e facilita o entendimento das pessoas.

Por outro lado, os fatores sinergia entre as áreas, limitação de recursos e autonomia da área de TI, que eram indefinidos na análise antes da fusão, agora se definiram. O fator de sinergia entre as áreas passou a só promover o alinhamento. Tal condição parece mesmo indispensável à realização da fusão dos processos e dos sistemas das empresas. Já os fatores limitação de recursos e autonomia da área de TI passaram a só inibir. A explicação decorre da constatação de que passou a existir forte centralização das decisões de TI na matriz da empresa adquirente, fora do país, além de que se ampliou, pela mesma razão, o processo de limitação de recursos.

Os fatores prioridade do negócio e gestão de projetos deixaram de inibir o alinhamento e passaram a promovê-lo. Essa mudança sofreu influência do aumento da prioridade do negócio do Wal-Mart no Brasil e da realização dos projetos de integração.

Constata-se, ainda, que: (i) os fatores qualificação dos profissionais e uso de metodologia nos projetos continuaram como promotores do alinhamento; (ii) comunicação das metas e tratamento das necessidades locais permaneceram no limbo da indefinição; (iii) planejamento e centralização da TI permaneceram como fatores inibidores do alinhamento.

Por fim, outro ponto a ser ressaltado em relação aos grupos de percepções é que, durante o processo de fusão, alguns fatores passaram a ser relatados por todos os entrevistados de ambas as áreas do Bompreço e do Wal-Mart. Essa visão afinada e global não ocorria na percepção do processo de antes da fusão. 


\section{Detalhamento dos Fatores Específicos}

Evidencia-se que para os fatores específicos é muito mais nítida a segregação entre os fatores promotores e os fatores inibidores do alinhamento entre a estratégia de TI e a estratégia empresarial. Dos quinze fatores levantados, nove são inibidores, três indefinidos, e apenas três são considerados fatores promotores. Ademais, a predominância de fatores inibidores é destacada. Isso já era, em parte, esperado por causa do intenso processo de mudanças que ocorre ao mesmo tempo em todas as áreas da nova empresa em virtude da fusão.

Também de forma previsível, as áreas do Bompreço (TI e de negócio) visualizaram, de forma bem mais enfática, o tratamento das mudanças como inibidor do processo de alinhamento, pois a empresa adquirida sofre muito mais impactos no processo de fusão que a empresa adquirente.

Para demonstrar quão ostensiva foi a predominância dos fatores inibidores em relação aos promotores, sete dentre os respondentes não conseguiram perceber nenhum fator que promovesse o alinhamento entre a estratégia de TI e a estratégia empresarial durante o período de fusão, ou seja, para eles todas as condições decorrentes do processo de fusão inibem a busca do alinhamento. Por sua vez, somente um entrevistado, da área de negócios da empresa adquirente, não vislumbrou nenhum aspecto que dificultasse o alinhamento perseguido. A Figura 5 exibe a separação dos fatores taxados como específicos.

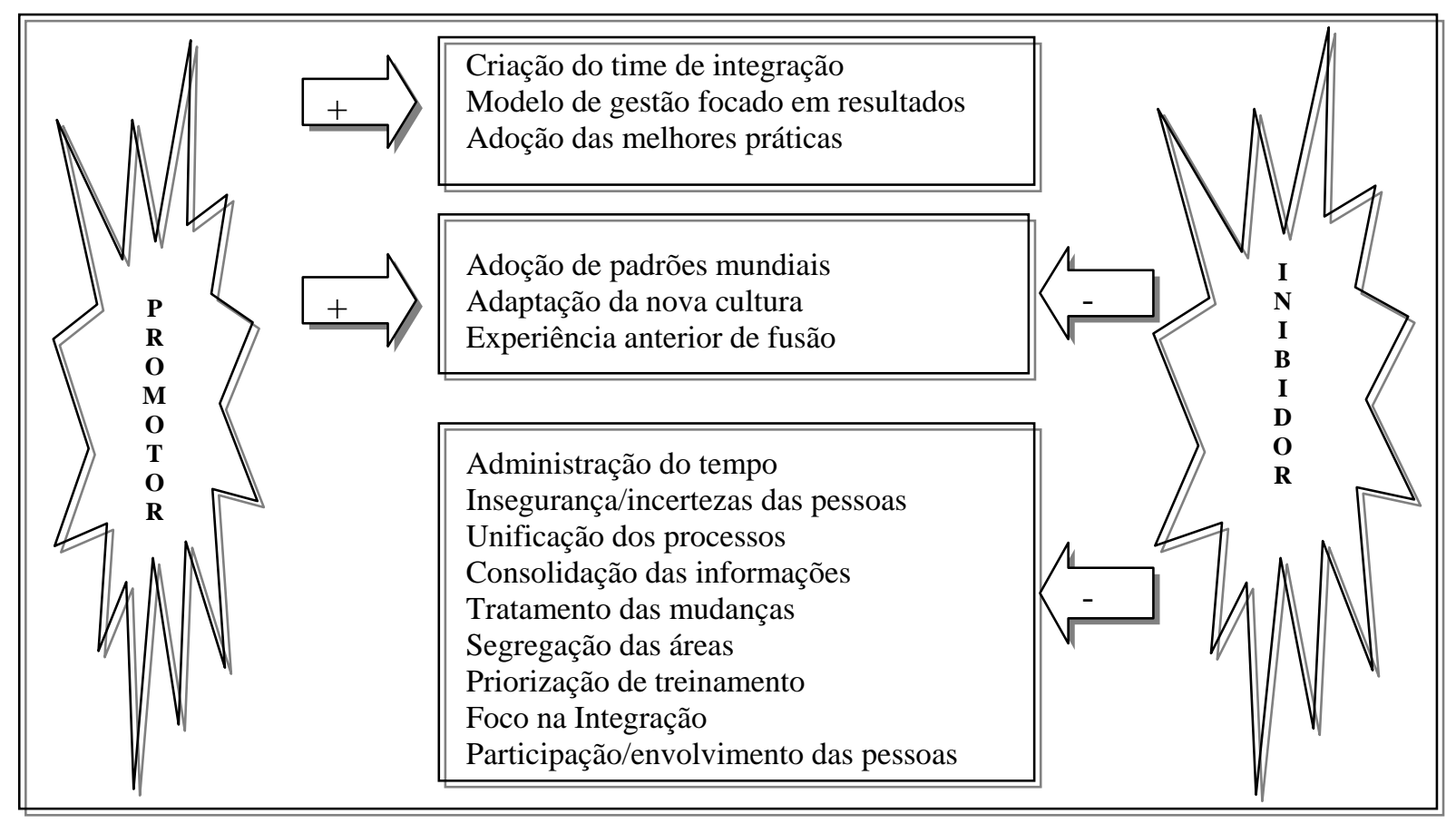

Figura 5. Fatores Promotores e Inibidores - Específicos da Fusão

Fonte: Pereira, C. M. L. (2006). Fatores promotores e inibidores do alinhamento estratégico da tecnologia da informação em uma situação de fusão: o caso de uma rede varejista. Dissertação de mestrado, Universidade Federal de Pernambuco, Recife, PE, Brasil, p. 96.

A Figura 5 denota que a inibição do alinhamento foi fortemente associada a fatores, tais como: administração do tempo, tendo em vista que era preciso realizar a integração de processos conjuntamente com a manutenção das atividades do dia-a-dia; insegurança e incertezas das pessoas em função da pouca atenção dada aos aspectos relacionados aos fatores humanos; dificuldade na unificação dos processos devido à demora na conversão de sistemas; dificuldade de consolidação das informações pela perda no processo decisório.

Em menor escala, mas ainda com grande intensidade, foram reportados como fatores inibidores: tratamento das mudanças e segregação das áreas, devido à existência de dois processos funcionais e 
dois sistemas distintos sendo executados em paralelo; falta de priorização de treinamento para a adaptação às novas realidades; foco maior na integração, fazendo com que os processos atuais fiquem sem manutenção.

Há pouca indefinição dentre os fatores específicos, mas a adoção de padrões mundiais, a adaptação à nova cultura e a experiência anterior de fusão podem ora inibir, ora promover o alinhamento na visão dos respondentes de ambas as empresas.

Por fim, os fatores promotores do alinhamento foram: a criação de um time de integração com participação de pessoas das duas empresas em todas as áreas funcionais, para ajudar na integração dos processos e sistemas; a adoção das melhores práticas existentes, visando à sua implementação nos sistemas globais, seja pela realização do mapeamento dos processos atuais e do levantamento das diferenças existentes, seja dando oportunidade ao tratamento de necessidades locais; a idealização de um modelo de gestão focado em resultados.

\section{DISCUSSÕES}

Os resultados do estudo foram obtidos considerando dois momentos: antes da fusão e no seu desenrolar. No período antes da fusão, pessoas de ambas as empresas concordaram que existia alinhamento entre as estratégias de TI e empresarial. Todavia, houve um elemento específico para este caso, que se pode configurar como relevante contribuição para estudos futuros do tema alinhamento em ambientes de fusão: a distinção de maturidade na gestão de TI entre as empresas que se fundem e sua influência no andamento e condução do processo.

De fato, em se tratando de TI, as estruturas das empresas eram muito diferentes. Enquanto a empresa adquirida tinha uma estrutura de TI local forte, a empresa adquirente tinha sua área de TI centralizada na matriz, nos Estados Unidos. Havia, pois, uma diferença de suporte e de atendimento das necessidades mediatas de TI entre a visão global e local. Isto, inevitavelmente, conduziu a diferentes percepções quanto à promoção e inibição do alinhamento na ótica da área de TI. Este é um dado revelado no campo e que merece ser explorado. Ou seja, investigar quais preocupações adicionais em processos de fusão devem ser consideradas para o sucesso do alinhamento estratégico da TI e da plataforma dos negócios, quando as empresas originais têm na esfera local diferentes níveis de maturidade em gestão de TI e a adquirida é mais estruturada, mas será governada pelas regras da empresa adquirente em nível global.

Outro dado marcante, que também figura como resgate da pesquisa, foi a detecção da assincronia decorrente do planejamento isolado de áreas que deveriam convergir. Em processo de fusão, a nova realidade gera conflito de prioridades para a gestão dos projetos e isto permite que, muitas vezes, alguns projetos de menor retorno para a empresa fusionada (visão global) sejam priorizados em detrimento de projetos mais importantes na visão local. Eis um dado também para ser catalogado como elemento importante para configurar a gestão de alinhamento estratégico em empresas que estão em processo de fusão.

Já durante a análise do período da fusão, ficou evidenciado que existiam, além de fatores gerais (recorrentes), fatores específicos do processo de fusão. No novo conjunto de fatores, um fator inibidor específico que mereceu destaque, foi o tratamento das mudanças, pois existiam muitos elementos novos que precisavam ser tratados, sendo introduzidos em todas as áreas da empresa, ao mesmo tempo.

Sabe-se que as mudanças nas empresas são tão constantes, que a teoria organizacional visualiza o tratamento da mudança como competência crítica para o sucesso empresarial (Rockart, Earl, \& Ross, 1996). Eis, então, o vislumbre pelo qual o fator tratamento da mudança deve ser priorizado na busca do alinhamento em um processo de fusão, porquanto, se esta ação não for bem conduzida, 
irremediavelmente esse fator será forte inibidor de todo o processo. Essa premissa é sustentada por Xavier e Dornelas (2004), que afirmam que o planejamento da mudança deve defender a transformação proposta e demonstrar suas necessidades e vantagens para gerar o envolvimento e comprometimento das pessoas.

Também nessa direção, Hardy (1994) e Robbins (1997) argumentam que, dada a resistência que pode ocorrer em uma estrutura transplantada, deve haver catalizadores dentro das empresas para promover a mudança. Daí, a importância dos recursos humanos para o alinhamento entre a estratégia de TI e a estratégia de negócios. Talvez tal foco mereça atenção redobrada, já que as pessoas, em casos como este, ficam muito mais sensíveis, inseguras e resistentes, devido às mudanças.

Outros pontos importantes bem específicos desta fusão, merecedores de atenção, no âmbito geral, e facilitadores do incremento do alinhamento, foram: a) a criação de times de integração em todas as áreas funcionais da empresa e na área de TI, com o intuito de aumentar o conhecimento mútuo das duas empresas; b) a chance que foi dada para que a necessidade local, já especificada em sistemas, fosse incorporada aos sistemas globais, mediante a solicitação à área de TI internacional; c) a adoção de um modelo de gestão focado em resultados.

Por outro lado, fatores que afetaram negativamente o alinhamento da estratégia de TI com a estratégia empresarial no processo de fusão e merecem ser citados foram: a) dificuldade de administração do tempo, tendo em vista que era preciso realizar a integração conjuntamente com o suporte à manutenção da atividade cotidiana; b) demora na unificação de processos e sistemas, pois a consolidação das informações, dispostas em duas plataformas distintas, não era tarefa trivial.

Ambas as dificuldades indicam que a integração dos processos e a coexistência de rotinas precisam ser ressaltadas, pois a desatenção nesse foco provoca forte influência negativa no processo de alinhamento estratégico em empresas que estão em processo de fusão.

Reforçam-se, ainda, como fatores inibidores bem específicos desta fusão, a centralização da área de TI, que dificultava todo o suporte das necessidades locais, principalmente de médio e longo prazo, e a dificuldade de comunicação pela barreira da língua.

Todavia, na vaga de fusões ou aquisições como a relatada neste caso, tais indicativos podem vir, também eles, a merecer estudos mais detalhados como influentes no caso geral de alinhamento estratégico.

No início do processo de fusão, seria normal, segundo a maioria dos respondentes, uma tendência à diminuição do alinhamento. No entanto, como esta pesquisa foi realizada depois de um ano e meio do início do processo de fusão, a opinião geral foi que o alinhamento aumentou ao longo desse tempo, porque as pessoas já vivenciavam mais a cultura e as estratégias da nova empresa, as áreas começavam a ser estruturadas e a mesclagem dos profissionais era cada vez maior, gerando adoção de melhores práticas.

Por fim, é importante salientar a relação que pôde ser estabelecida entre os fatores levantados na literatura e os fatores verificados no caso estudado. Essa relação gerou a figura 6 e nela percebe-se que todos os fatores abordados na literatura podem ser associados a outros que emergiram do estudo, exceto o fator falha na implementação. 


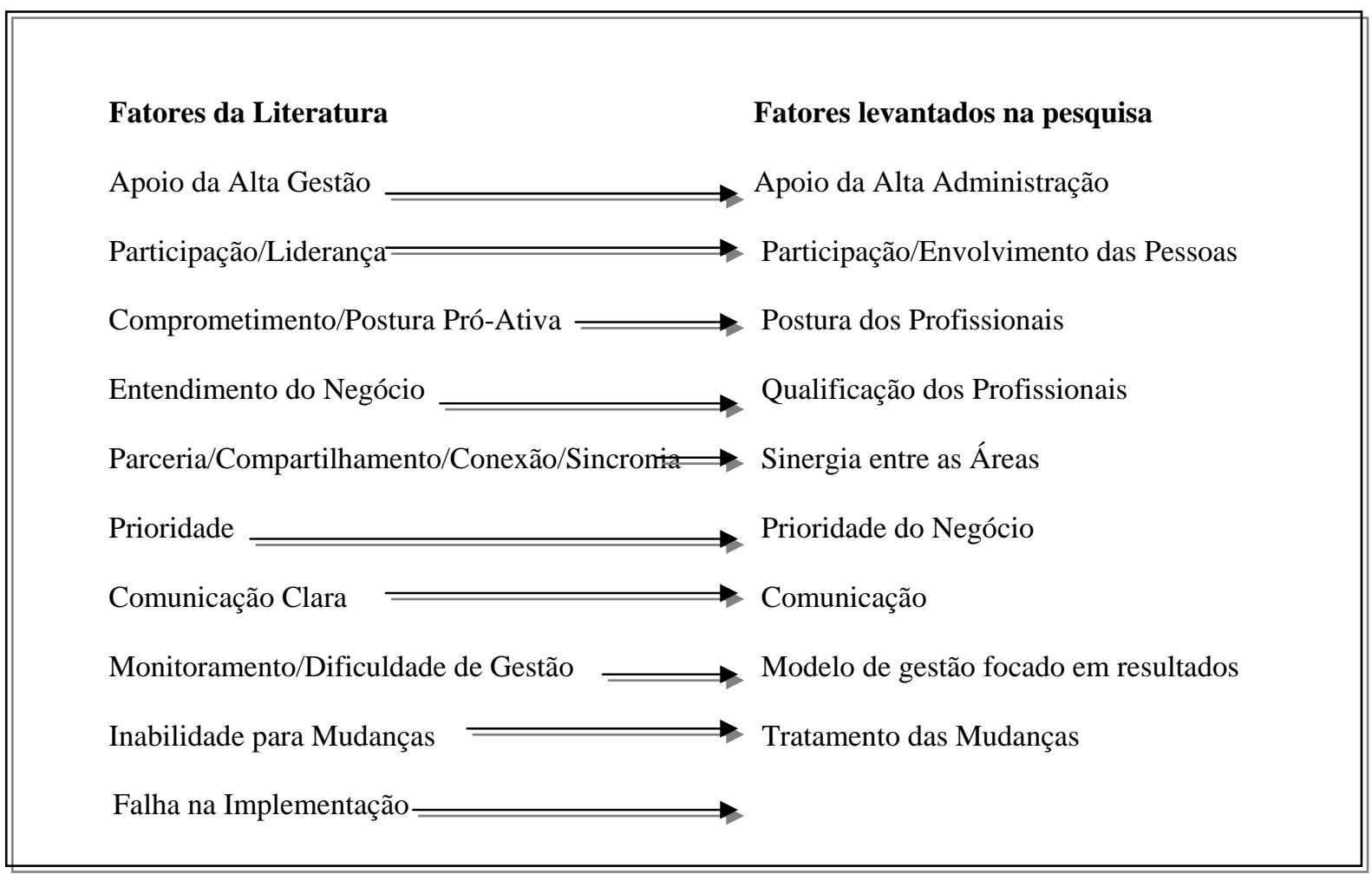

Figura 6. Relação entre os Fatores da Literatura e os Fatores Levantados no Caso

Fonte: Pereira, C. M. L. (2006). Fatores promotores e inibidores do alinhamento estratégico da tecnologia da informação em uma situação de fusão: o caso de uma rede varejista. Dissertação de mestrado, Universidade Federal de Pernambuco, Recife, PE, Brasil, p. 124.

Quanto à expectativa dos respondentes no que diz respeito ao alinhamento entre a estratégia de TI e a estratégia empresarial, após o término de todo o processo de fusão, há bons indícios de que ele será positivo, em virtude do modelo de gestão focado em resultados.

\section{CONSIDERAÇÕES FinAIS}

Este estudo permitiu elucidar dois momentos de um processo de alinhamento estratégico, algo ainda pouco explorado em ambientes de fusão empresarial. Mesmo não cogitando a possibilidade de generalizações, este estudo de caso pode subsidiar estudos futuros de alinhamento em casos de fusão de empresas. Tais estudos poderão ocorrer em empresas do mesmo segmento, mas escolhendo casos de fusão de empresas nacionais. Projeta-se ainda, por exemplo, que este mesmo tipo de estudo pode ser realizado em um caso de fusão de empresas públicas, nas quais, certamente, outros fatores deverão aparecer, em função das peculiaridades das organizações desse segmento.

O estudo possui limitações inerentes às suas técnicas, aqui reconhecidas. As principais delas foram as especificadas a seguir.

- Não se tratar de um estudo longitudinal, em que as entrevistas se repetiriam ao longo do processo de fusão, em momentos distintos: início, meio e fim do processo.

- Necessidade de tratamento das particularidades locais e das legislações diferentes, por se tratar da fusão de uma empresa internacional com uma empresa nacional.

- Tratar-se de estudo de caso único, de empresa privada varejista, não propiciando ver as percepções adicionais do mercado/segmento. 
Por fim, a dinâmica da pesquisa consiste em explorar terrenos ainda desconhecidos em busca de objetivos traçados e, neste caso em particular, a meta a ser alcançada era identificar elementos (fatores) que promovessem ou inibissem o alinhamento estratégico da tecnologia da informação com o negócio em um caso de fusão de empresa em ambiente varejista.

Espera-se, assim, ter contribuído com o estudo para a disseminação e desenvolvimento do conceito de alinhamento estratégico da tecnologia da informação, bem como ter ampliado o conhecimento sobre fatores que promovem e inibem esse alinhamento, para ajudar a conquistar a tão almejada vantagem competitiva organizacional.

\section{Artigo recebido em 20.03.2007. Aprovado em 30.04.2009.}

\section{REFERÊNCIAS BIBLIOGRÁFICAS}

Ansoff, H. I. (1990). A nova estratégia empresarial. São Paulo: Atlas.

Brodbeck, A. F., Hoppen, N., Oliveira, A. S., \& Majdenbaum, A. (2003, setembro). Alinhamento entre objetivos organizacionais e sistemas de informação: um estudo de múltiplos casos. Anais do Encontro Nacional da Associação Nacional de Pós-Graduação e Pesquisa em Administração, Atibaia, SP, Brasil, 27.

Bruhn, P. R. L. (2004, junho). Alinhamento estratégico de TI: importância, modelos e relações. Anais do Congresso Anual de Tecnologia da Informação, São Paulo, SP, Brasil, 1.

Chan, Y. E. (2002). Why haven't we mastered alignment? The importance of the informal organization structure. MIS Quarterly Executive, 1(2), 97-112.

Chan, Y. E., Huff, S. L., Barclay, D. W., \& Copeland, D. G. (1997). Business strategic orientation, information system strategic orientation, and strategic alignment. Information Systems Research, 8(2), 125-150.

Grover, S. K., \& Lederer, A. L. (2003). A resource-based view of strategic it alignment: how knowledge sharing creates competitive advantage. Decision Sciences, 34(1), 1-29.

Hardy, C. (1994). Managing strategic change. Thousand Oaks, CA: Sage Publications.

Henderson, J. C., \& Venkatraman, N. (1991). Understanding strategic alignment. Business Quarterly; ABI/INFORM Global, 55(3), 72-74.

Henderson, J. C., \& Venkatraman, N. (1993). Strategic aligment: leveraging information technology for transforming organizations. IBM Systems Journal, 32(1), 472-484.

Hitt, M. A., Ireland, D., \& Hoskisson, R. (2002). Administração estratégica: competitividade e globalização. São Paulo: Pioneira Thompson Learning.

Kotler, P. (1999). Marketing para o século XXI: como criar, conquistar e dominar mercados. São Paulo: Futura.

Luftman, J. (1997). Align in the sand, leadership series computerworld. ABI/INFORM Global, 3(2), 111.

Luftman, J. (2000). Assessing business-IT alignment maturity. Communications of the Association for Information Systems, 4(1), 5-9. 
Luftman, J., \& Brier, T. (1999). Achieving and sustaining business-IT alignment. California Management Reviews, 42(1), 109-122.

Luftman, J., Lewis, P., \& Oldach, S. (1993). Transforming the enterprise: the alignment of business and information technology strategies. IBM Systems Journal Armonk, 32(1), 198-224.

Luftman, J., Papp, R., \& Brier, T. (1999). Enablers and inhibitors of business-it alignment. Communications of the Association for Information Systems, 1(11), 4-15.

Osgood, R. T. (2004). Translating organisational strategy into real estate action: the strategy alignment model. Journal of Corporate Real Estate London, 6(2), 106-118.

Papp, R., \& Luftman, J. (1995, August). Business and IT strategic alignment: new perspectives and assessments. Proceedings of the Association for Information System, Inaugural Americas Conference on Information Systems, Pittsburgh, PA, USA, 1.

Pereira, C. M. L. (2006). Fatores promotores e inibidores do alinhamento estratégico da tecnologia da informação em uma situação de fusão: o caso de uma rede varejista. Dissertação de mestrado, Universidade Federal de Pernambuco, Recife, PE, Brasil.

Porter, M. E. (1986). Estratégia competitiva: técnicas para análise de indústrias e da concorrência. Rio de Janeiro: Campus.

Reich, B. H., \& Benbasat, I. (1996). Measuring the linkage between business and information technology objectives. MIS Quarterly, 20, 55-81.

Reich, B. H., \& Benbasat, I. (2000). Factors that influence the social dimension of alignment between business and information technology objectives. MIS Quarterly, 24(1), 81-113.

Rezende, D. A. (2002). Alinhamento do planejamento estratégico da tecnologia da informação ao planejamento empresarial: proposta de um modelo e verificação da prática em grandes empresas brasileiras. Tese de doutorado, Universidade Federal de Santa Catarina, Florianópolis, SC, Brasil.

Robbins, S. P. (1997). Essentials of organizational behavior. Uppersaddle River, NJ: Prentice Hill.

Rockart, J. F., Earl, M. J., \& Ross, J. W. (1996). Eight imperatives for the new IT organization. Sloan Management Review, 38, 43-55.

Stake, R. E. (1994). Case studies. In N. K Denzin \& Y. S. Lincoln (Eds.), Handbook of qualitative Research (pp. 236-247). Thousand Oaks, CA: Sage Publications.

Suen, A. S., \& Kimura, H. (1997). Fusão e aquisição como estratégia de entrada (entre mode) no mercado brasileiro. Caderno de Pesquisas em Administração, 2(5), 53-60.

Walton, R. E. (1993). Tecnologia da informação: o uso de TI pelas empresas que obtêm vantagem competitiva. São Paulo: Atlas.

Xavier, R. O., \& Dornelas, J. S. (2004, setembro). O papel do gerente numa mudança organizacional baseado em tecnologia. Anais do Encontro Nacional da Associação Nacional de PósGraduação e Pesquisa em Administração, Curitiba, PR, Brasil, 28.

Yin, R. (2001). Estudo de caso: planejamento e métodos. São Paulo: Bookman. 